\title{
Usefulness of C-Arm Fluoroscopy in Treating Patients Injured by a Shotgun
}

\author{
Pil Young Jung', Ki Youn Kwon² \\ ${ }^{1}$ Department of Surgery, Yonsei university Wonju college of medicine, Wonju Severance Christian Hospital, Trauma center \\ ${ }^{2}$ Department of Orthopedics, Yonsei University Wonju college of medicine, Wonju Severance Christian Hospital
}

Shotgun injury, a rare event, is difficult to treat. Moreover, it is annoying and difficult to locate and remove bullets from patients using surgery. Here, we describe here a shotgun injury case wherein we removed the bullets using C-Arm fluoroscopy.

(Trauma Image Proced 2018(1):23-24)

Key Words: Gunshot wounds; Fluoroscopy; Foreign body

\section{CASE}

A 79-year-old male with no medical history was admitted to the emergency room with multiple shotgun injuries. He was mistakenly shot by a hunter hunting for a water deer. Upon admission, the patient was hemodynamically stable, but showed multiple shotgun injuries on the head, chest, abdomen, forearm, and leg (Fig. 1.). Further, he had hemoperitoneum and peritonitis because of bowel perforation and a mesentery injury. We accordingly planned for an emergency abdominal surgery followed by an orthopedic surgery (Fig. 2.). We employed C-Arm fluoroscopy to accurately locate the bullets in his body and to check for any remaining bullets. All bullets were removed using C-Arm fluoroscopy (Fig. 3.). The patient recovered without any complications.

\section{DISCUSSION}

High-velocity firearm bullets travel at a speed of $>2000 \mathrm{ft} / \mathrm{s}$ and transfer high energy to the tissues, whereas those of low-velocity weapons travel at $<1000$ $\mathrm{ft} / \mathrm{s}$. Shotgun is an example of the latter type. A shotgun cartridge contains pellets of varying sizes (very small to large) (1). Therefore, it is difficult to locate and remove these bullets from patients injured by a shotgun. In conclusion, C-Arm fluoroscopy is a useful modality for treating patients injured by a shotgun.

\section{Conflict of Interest Statement}

No potential conflict of interest relevant to this article was reported.

Received: April 4, 2018 Revised: May 16, 2018 Accepted: May 17, 2018

Correspondence to: Pil Young Jung, Department of Surgery, Yonsei university Wonju college of medicine, Wonju Severance Christian Hospital, 220-701, 20 IIsan-ro, Wonju-si, Gangwon-do, South Korea

Tel: 82-33-741-0882, Fax: 82-33-741-0574, E-mail: surgery4trauma@yonsei.ac.kr

Copyright (c) 2018 Korean Association for Research, Procedures and Education on Trauma. All rights reserved.

(c) This is an open-access article distributed under the terms of the Creative Commons Attribution Non-Commercial License (http://creativecommons.org/ licenses/by-nc/4.0) which permits unrestricted noncommercial use, distribution, and reproduction in any medium, provided the original work is properly cited 


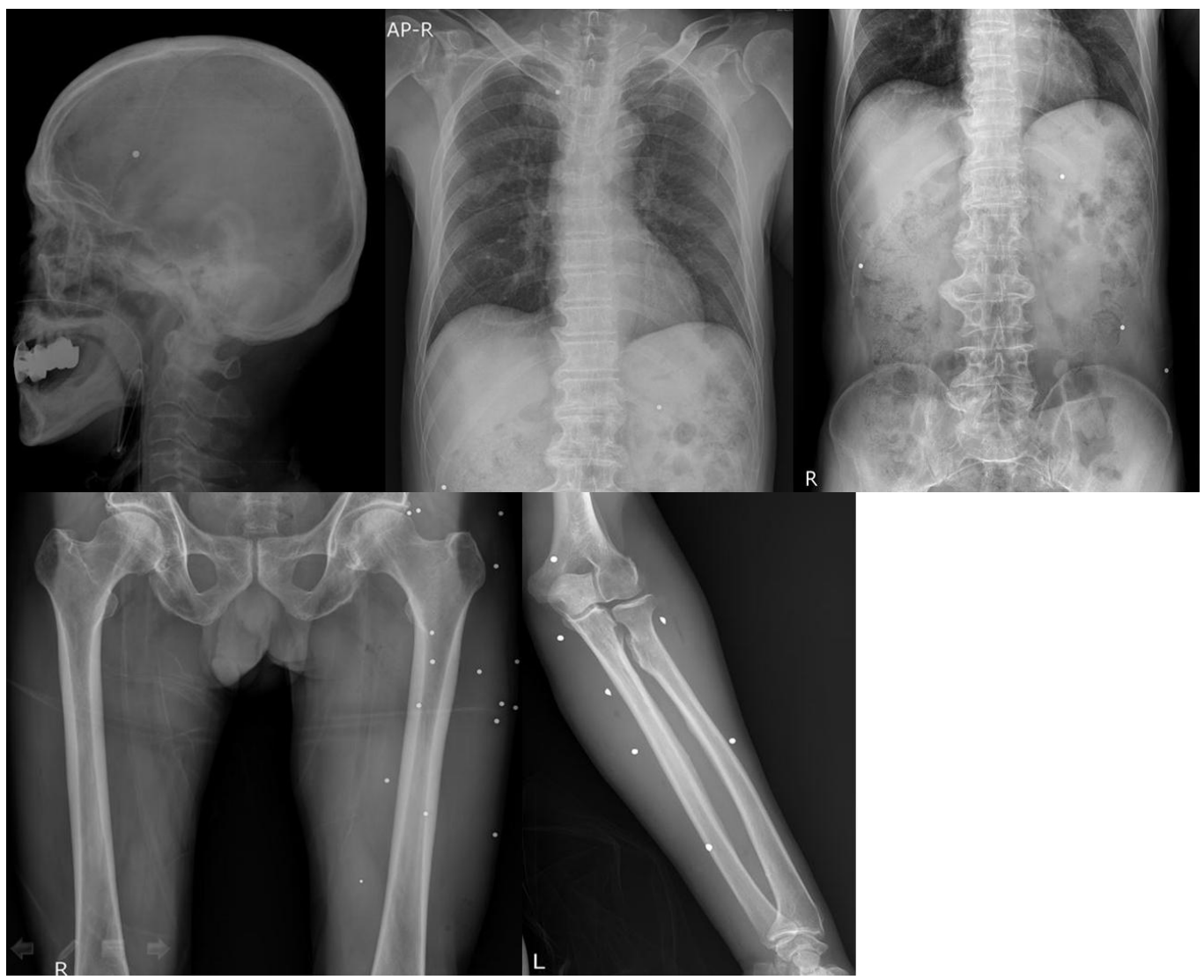

Fig. 1. Plain X-Ray indicating bullet wounds at multiple sites

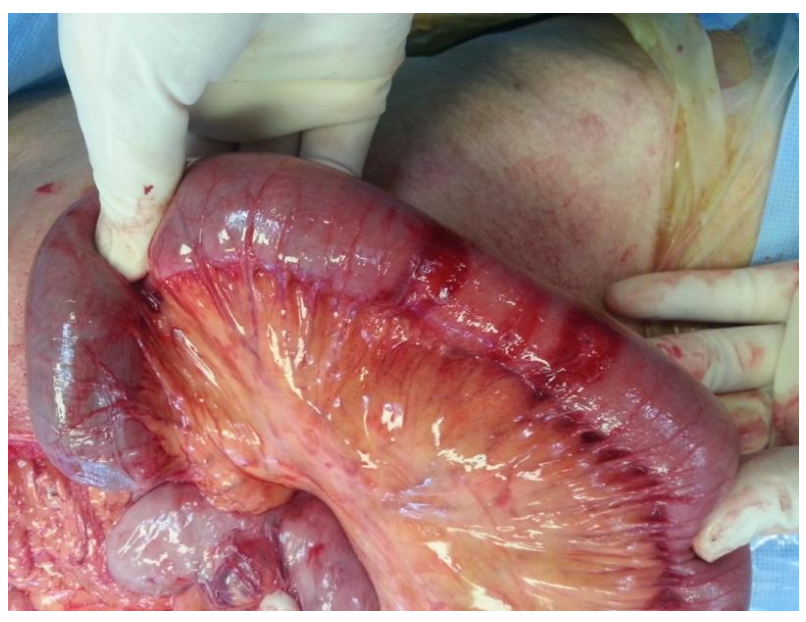

Fig. 2. Surgical finding of a small bowel injury

\section{REFERENCE}

1. Jaramillo PM, Montoya JA, Mejia DA et al. Nonoperative Management of Multiple Penetrating Cardiac and Colon

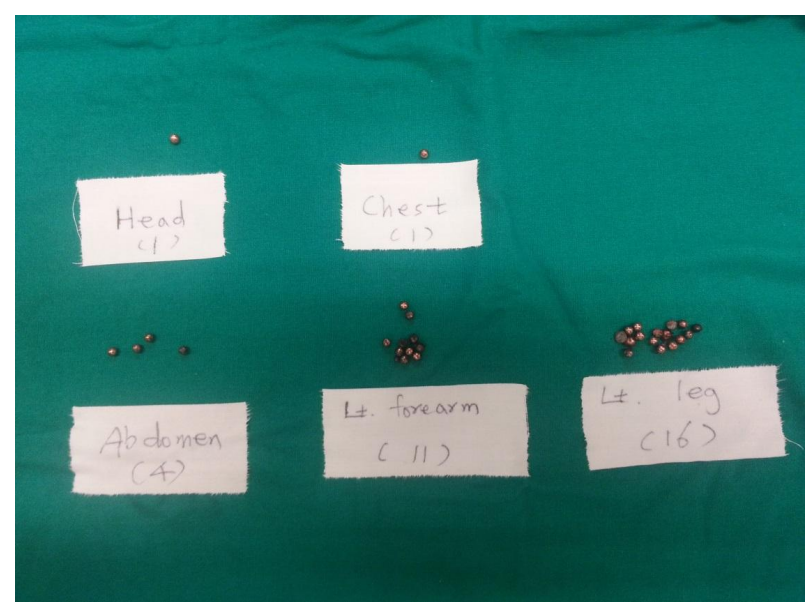

Fig. 3. Total bullets removed from the patient

Wounds from a Shotgun: A Case Report and Literature Review. Case Rep Surg. 2018 Jan 24; 2018: 7839465. 